\title{
The Accuracy of Confocal Laser Endomicroscopy in Diagnosing Bladder Cancer: A Systematic Review and Meta-Analyses
}

\author{
Hafizar $^{1^{*}}$, Etriyel Myh ${ }^{2}$ \\ ${ }^{1}$ Department of Urology, Cipto Mangunkusumo Hospital, Faculty of Medicine Universitas Indonesia, Jakarta, Indonesia \\ ${ }^{2}$ Division of Urology, M. Djamil General Hospital, Faculty of Medicine, Universitas Andalas, Padang, Indonesia
}

\section{ARTICLE INFO}

Received : 16 November 2020

Reviewed : 04 February 2021

Accepted : 21 May 2021

\section{Keywords:}

accuracy, biopsy, bladder cancer, confocal laser endomicroscopy

\author{
*Corresponding author: \\ Hafizar \\ Department of Urology, \\ Cipto Mangunkusumo Hospital, \\ Faculty of Medicine Universitas \\ Indonesia Jalan Diponegoro No. 71, \\ Senen, Jakarta Pusat, Indonesia, 10430 \\ hafizar.sr@gmail.com
}

\begin{abstract}
A BSTRACT
Background: Multiple advancements of endoscopic technology were designed to enhance the sensitivity and specificity of the diagnostic tools of bladder cancer; thus, we perform a meta-analysis to compare diagnostic performance between confocal laser endomicroscopy (CLE) and biopsy for detecting bladder cancer.
\end{abstract}

\begin{abstract}
Methods: We compared CLE's accuracy in diagnosing bladder cancer reported by studies obtained from the electronic database MEDLINE, CENTRAL, and CINAHL, from May to June 2020. The pooled effect estimate was calculated employing the DerSimonian and Laird random-effects model. We only included moderate to high-quality studies, which had been assessed by the QUADAS-2 tool.
\end{abstract}

\begin{abstract}
Results: Eight studies were included in this review; five of those were good-quality studies. A total of 519 samples from 345 patients were included in the pooled effect estimate calculation. Pooled sensitivity and specificity of CLE in diagnosing bladder cancer were $90.2 \%(0.86,0.93)$ and $78.1 \%(0.71,0.85)$, respectively. The use of white-light cystoscopy (WLC) before CLE increased its specificity $(56.8 \%$ versus $84.6 \%)$. Pooled sensitivity and specificity of CLE in predicting lowgrade lesion were $73 \%(0.66,0.80)$ dan $83 \%(0.78,0.87)$, respectively. Meanwhile, pooled sensitivity and specificity of CLE in predicting high-grade lesion were $73 \%(0.66,0.78)$ and $79 \%$ $(0.73,0.83)$, respectively.
\end{abstract}

Conclusions: CLE has good accuracy in distinguishing malignant and benign tumors. Grading tumors with this modality is also accurate. The use of probe CLE (pCLE), coupled with WLC, will increase its specificity.

\section{INTRODUCTION}

Bladder cancer is one of the most malignant cancers globally, placed as the sixth most common malignancy [1] The five-year relative survival rates of patients with breast, prostate, and colon cancer have increased by over $15 \%$, while the trend was elevated only merely by $6 \%$ for bladder cancer [2]. In addition, the incidence of bladder cancer has been shown to keep increasing remarkably in the developed nation, which can be associated with high productivity and bladder cancer risk factors, including alcohol, red meat consumption, smoking, and obesity. Bladder cancer incidence rate was also found to be the highest in Southern and Western Europe and North America. Meanwhile, the highest mortality rates were in Western Asia and Northern Africa [3].

There are three main types of bladder cancer, which are named after the type of cells. They are transitional cell carcinoma or sometimes called urothelial carcinoma (UCC), squamous cell carcinoma (SCC), and adenocarcinoma (ADC). UCC is derived from cells at the innermost tissue of the bladder tissue that functions to stretch when the bladder is full. It is the most common type of bladder cancer that accounts for almost $90 \%$ of bladder cancer [4]. SCC is emanated from the cell that lines the bladder, while $A D C$ is originated from glandular cells underneath the lining of the bladder. Moreover, the survival rate of bladder cancer is higher when the cancer is still localized 
(69\%) than when cancer has spread to distant organs (5\%) [2]. Unfortunately, bladder cancer has a notorious characteristic, it is a high tendency to relapse and its imminent progression risk $[5,6]$. This trend increases the frequency of follow-up schedules, making bladder cancer expensive cancer to treat [6]. Furthermore, the cancer was found to be invasive in around $10-15 \%$ of relapse cases [5]. Therefore, early yet accurate diagnosis and prompt treatment play an essential role in recognizing early relapse and minimizing the risk of tumor progression.

For diagnosing bladder cancer, cystoscopy/biopsy and urinary cytology remain the current gold standard [7]. White light cystoscopy (WLC) is initially used to determine the gross structure, location, size, and number of the tumor. WLC can also be employed as a guide for transurethral resection of bladder tumors (TURBT) [8]. However, WLC has very low sensitivity and specificity in detecting bladder cancer $(68.3 \%$ and $82.9 \%$, respectively) [9]. Several factors, including limited WLC visualization in distinguishing the borders of the tumor and margins of the submucosal tumor, contribute to the poor diagnosis [10]. It will lead to incomplete tumor resection, especially when multifocal lesions are presented [11]. In addition, a conventional biopsy cannot be performed accurately and should be replaced with a more specific tool, such as a real-time in vivo optical biopsy.

For this reason, multiple advancements of endoscopic technology were designed to enhance the sensitivity and specificity of the diagnostic tools. Several endoscopies have been designed to be able to accurately pinpoint the tumor location through fluorescent, enhanced visualization of the vasculature or nearinfrared light. For instance, photodynamic diagnosis (PDD) and narrow-band imaging (NBI) were utilized for macroscopic imaging, whereas confocal laser endomicroscopy (CLE) and optical coherence tomography (OCT) were used as microscopic imaging [12]. In addition, each endoscopic technology possesses its advantages and disadvantages. For instance, PDD and NBI are beneficial for observing suspicious lesions, while OCT and CLE are useful for tumor staging and grading [10].

CLE is an optical biopsy equipped with a high microscopic resolution with images comparable with a traditional histopathology biopsy sample. CLE is, by far, one of the optical biopsy technologies that can differentiate between low and high-grade bladder cancer [10]. Therefore, the purpose of this study is to perform a meta-analysis to compare CLE and biopsy diagnostic performance for detecting bladder cancer.

\section{METHODS}

\section{Description of condition and intervention}

This study aims to find the accuracy of the CLE modality in diagnosing bladder cancer. Therefore, this systematic review included studies comparing biopsy methods (golden standard) with CLE (index test) in diagnosing patients with suspected bladder cancer. We excluded studies describing the use of CLE in the detection or grading of urological cancer or pre-malignant disease processes without any restriction of CLE specification. CLE assessment employed CLE criteria as described by Chang et al. [13], which comprised papillary configuration, cell organization, the cohesiveness of cells, cellular morphology, the definition of cell borders, vasculature, and polarity.

\section{Database searching and literature screening}

A literature search was conducted in five electronic databases (MEDLINE, CENTRAL, CINAHL, Scopus, and ProQuest). We utilized PICOS to make it easier to track studies and identify the suitability of studies we found. We conducted this literature search from May to June 2020. We used specific keywords adjusted according to each database (Table 1). We also looked for references from other systematic reviews analyzing similar things. We also restricted studies written in Indonesian/English to be included in this systematic review.

\section{Study selection}

This systematic review's writing was based on preferred reporting items for systematic reviews and meta-analysis (PRISMA) statements and Standards for Reporting Diagnostic Accuracy Studies (STARD). The inclusion criteria for this study included: 1) Clinical studies according to PICOS; 2) English/Indonesian articles; 3) Full-text articles were available; 5) Published in the last ten years. This study's exclusion criteria consisted of studies in the form of systematic or metaanalysis, literature review, case reports, case series, editorial letters, studies on animals, and/or studies in the process of peer review (not yet published). Each author independently assessed the study eligibility by looking at the title and abstract and analyzing full-text for the remaining articles. Any discrepancies among authors were resolved by discussion.

\section{Data extraction and outcome of interest}

Each writer extracted data independently onto a pre-defined extraction sheet. We extracted data from study characteristics, including patient characteristics, study design, sample size, and diagnosis modalities. However, we did not restrict the type of CLE modality performed on patients. The biopsy method was also not restricted. Any disagreement was resolved by discussion.

Moreover, this systematic review aims to assess the accuracy of the bladder cancer diagnosis method using CLE. The primary outcome of interest was the sensitivity and specificity of CLE compared to biopsy. The secondary outcomes studied were feasibility, cost, and standard operative equipment. We used a $2 \times 2$ contingency table to assess the accuracy of the CLE examination results for each study. The accuracy reported by each study 
was then calculated employing the forest plot. We also utilized the Meta-Disc 1.4 application to compile these outcomes and create ROC curves, using the DerSimonian and Laird random-effects model.

\section{Assessment of methodologic quality}

This systematic review included diagnostic studies with both experimental and observational designs. We assessed the risk of bias in all studies using the Quality Assessment of Diagnostic Accuracy Studies (QUADAS-2) tool [14]. We only included studies of at least moderate quality in meta-analysis.

\section{RESULTS}

\section{Literature search}

A search with specific keywords in five electronic databases found 459 articles, with 31 articles found in more than one database. We screened titles and abstracts in the remaining articles and found 20 studies that we thought were following our PICOS systematic review. However, after we analyzed the article's full text, only eight studies were in accordance with this PICO systematic review. PRISMA flow chart describing the process for identifying included articles can be seen in Figure 1.

\section{Study characteristics}

Eight studies were included in this systematic review. Among these eight studies, only two studies were published before 2015. Seven studies analyzed CLE's ability in tumors grading (high/low-grade), and six studies investigated CLE's ability to differentiate malignant from benign tumors. Based on each study's population, this systematic review involved 345 patients and 519 tissue samples. These studies spread across three continents, America, Asia, and Europe, most of which were conducted in Europe (Table 2).

This systematic review also tried to analyze the accuracy of a measuring instrument in diagnosing a condition; therefore, diagnostic studies were included in this review. To assess the quality of these diagnostic studies, we utilized the Quality Assessment of Diagnostic Accuracy Studies (QUADAS-2) tool. In general, the studies we included were of moderate to good quality. Only three studies had moderate quality. The results of the risk assessment bias can be found in Figure 2 .

\section{CLE accuracy in differentiating malignant and benign tumors}

Most studies reported that CLE had high sensitivity in differentiating malignant tumors from benign tumors. Five experiments in four studies reported a sensitivity of more than $90 \%$. Only the study of Marien et al. [21] reported sensitivity below $80 \%$. We conducted a pooling effect estimate using Mosses-Litenberg's Bivariate Model and found a pooled sensitivity of $90.2 \%(0.86,0.93)$. The result is shown in Table 3 .

CLE's specificity in determining malignant lesions is not as excellent as its sensitivity. 4 out of 7 experiments reported specificity at> $70 \%$. However, the other 3 showed very low results. After we conducted a metaanalysis with the random effect model, we found a pooled specificity of $78.1 \%(0.71,0.85)$. The area under the Curve was recorded at 0.9033 (0.0279), which indicates that CLE has high sensitivity and a low false-positive rate. The results of the pooling effect estimate are in Figure 3.

Table 1. Literature finding's result

\begin{tabular}{|c|c|c|c|c|}
\hline Database & Keywords & Hit & Selected & Comments \\
\hline MEDLINE & $\begin{array}{l}\text { ((((bladder cancer[MeSH Terms]) OR (bladder tumor[MeSH Terms])) } \\
\text { OR (bladder tumors[MeSH Terms])) OR (urothelial carcinoma)) AND } \\
\text { ((confocal laser scanning microscopy[MeSH Terms]) OR (confocal } \\
\text { laser endomicroscopy)) } \\
\text { Limit to: clinical trial }\end{array}$ & 3 & 1 & $\begin{array}{l}1 \text { not match PICOS } \\
1 \text { excluded after } \\
\text { full-text analysis as no } \\
\text { outcome measure } \\
\text { estimated }\end{array}$ \\
\hline CENTRAL & $\begin{array}{l}\text { "confocal laser endomicroscopy" in All Text AND "bladder cancer" } \\
\text { OR "bladder tumor" OR "bladder tumors" OR "urothelial cell } \\
\text { carcinoma" in All Text AND "sensitivity" OR "specificity" OR } \\
\text { "accuracy" in All Text - (Word variations have been searched) }\end{array}$ & 0 & 0 & - \\
\hline CINAHL & $\begin{array}{l}\text { TX "confocal laser endomicroscopy" AND TX ("bladder cancer" OR } \\
\text { "bladder tumor" OR "bladder tumors" OR "urothelial cell } \\
\text { carcinoma") AND TX ("sensitivity" OR "specificity" OR "accuracy") }\end{array}$ & 74 & 4 & $\begin{array}{l}54 \text { not match PICOS } \\
16 \text { article review }\end{array}$ \\
\hline Scopus & $\begin{array}{l}\text { ALL(“confocal laser endomicroscopy") AND ALL(“bladder cancer" } \\
\text { OR "bladder tumor" OR "bladder tumors" OR "urothelial cell } \\
\text { carcinoma") AND ALL("sensitivity" OR "specificity" OR "accuracy") }\end{array}$ & 168 & 4 & $\begin{array}{l}121 \text { not match PICOS } \\
40 \text { article review } \\
3 \text { pilot study }\end{array}$ \\
\hline ProQuest & $\begin{array}{l}\text { (confocal laser endomicroscopy) AND ("bladder cancer" OR } \\
\text { "bladder tumor" OR "bladder tumors" OR "urothelial cell } \\
\text { carcinoma") AND ("sensitivity" OR "specificity" OR "accuracy") }\end{array}$ & 205 & 3 & $\begin{array}{l}155 \text { not match PICO } \\
43 \text { article review } \\
4 \text { pilot study }\end{array}$ \\
\hline
\end{tabular}


Figure 1. PRISMA flow chart describing the process for identifying included articles

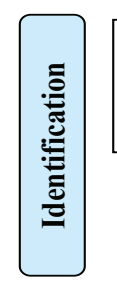

Records identified through database

$$
\begin{aligned}
& \text { searching } \\
& (\mathrm{n}=459)
\end{aligned}
$$

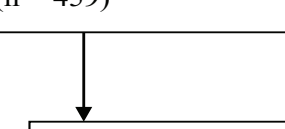

Records after duplicates removed

$$
(\mathrm{n}=428)
$$
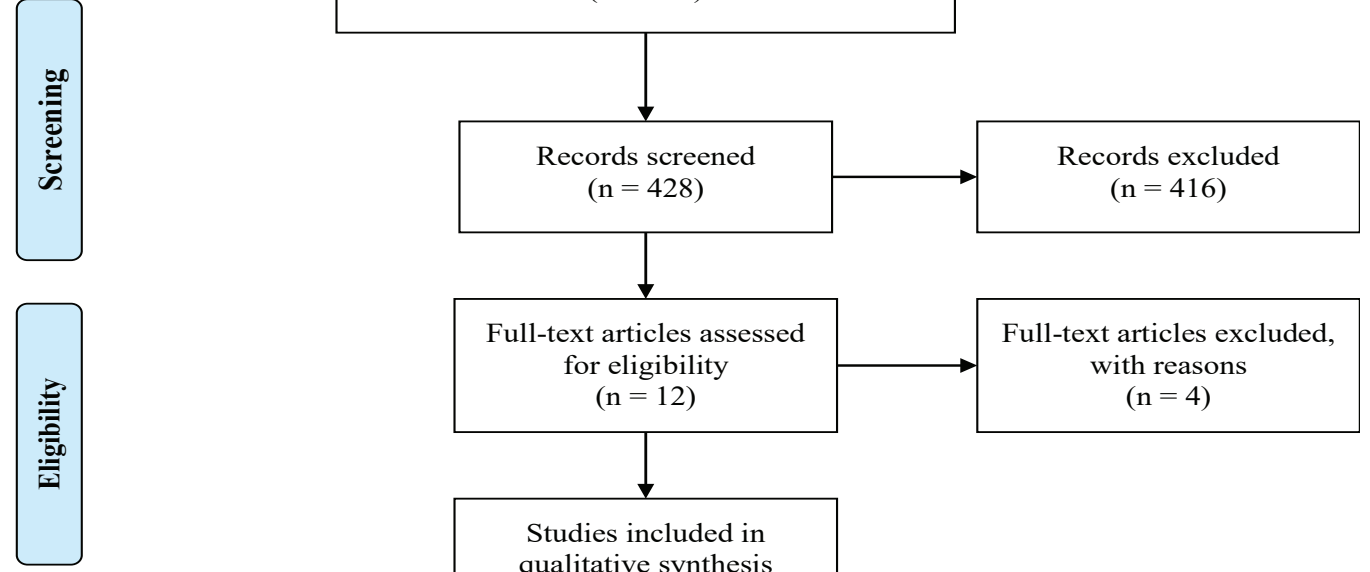

Full-text articles excluded, with reasons $(n=4)$

Studies included in qualitative synthesis $(\mathrm{n}=8)$

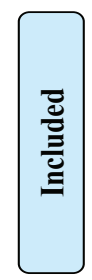

Studies included in quantitative synthesis (meta-analysis) $(\mathrm{n}=8)$
Figure 2. Risk of bias assessment of RCTs using Cochrane Risk of Bias Assessment.

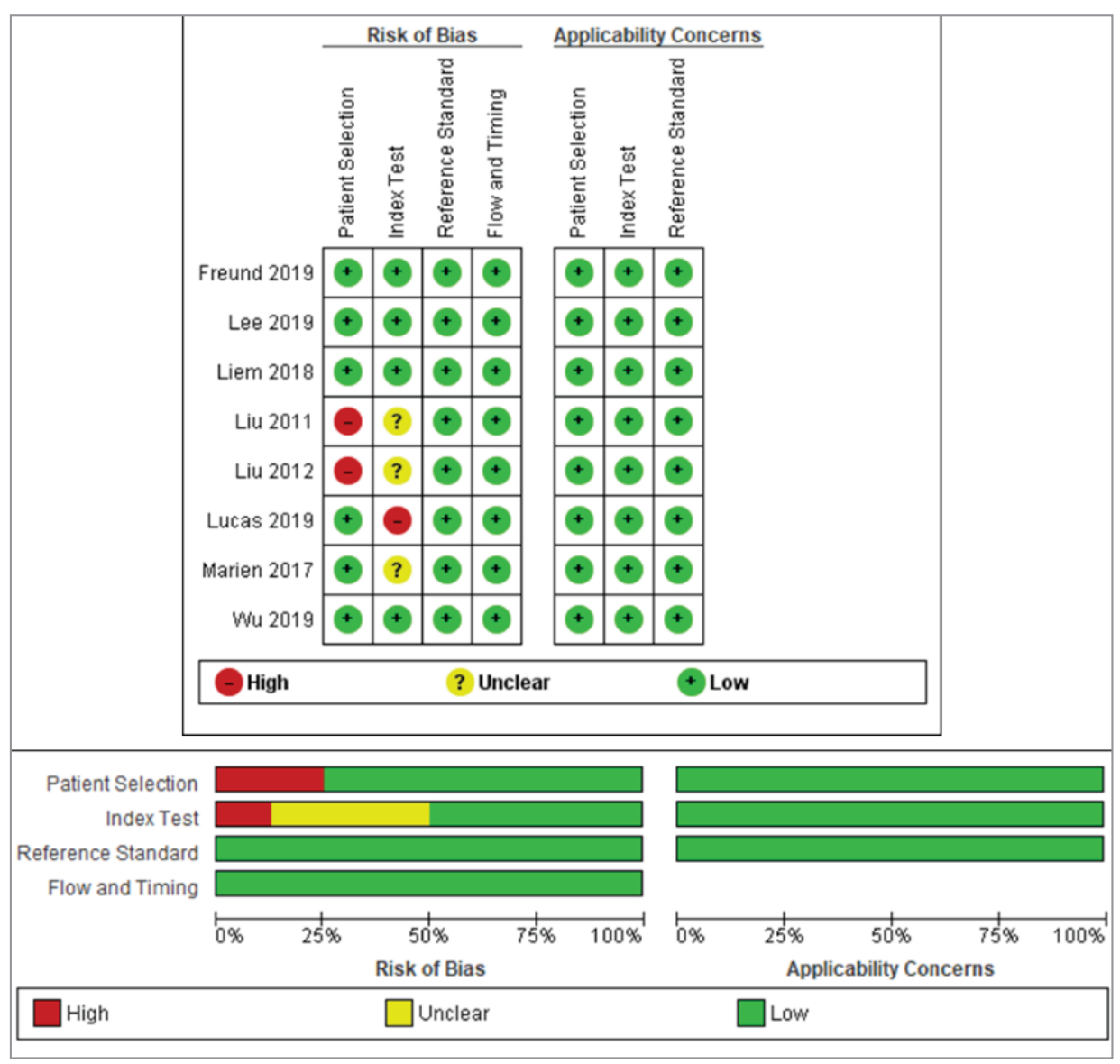


Table 2. Characteristics of the study included in this systematic review

\begin{tabular}{|c|c|c|c|c|c|c|c|}
\hline Author & Country & $\mathbf{N}$ & Age & Lesions ( $n$ ) & $\%$ male & Outcome & Design \\
\hline Freund, et al. (2019). ${ }^{15}$ & Netherland & 36 & $70 \pm 11$ & 53 & 69 & Grading high/low grade tumor & $\begin{array}{l}\text { Prospective } \\
\text { clinical trial }\end{array}$ \\
\hline Lee, et al. (2019). ${ }^{16}$ & $\begin{array}{l}\text { South } \\
\text { Korea }\end{array}$ & 75 & $68.32 \pm 9.45$ & 119 & 86.7 & $\begin{array}{l}\text { Differentiating benign/ } \\
\text { malignant lesion, grading high/ } \\
\text { low-grade malignant tumor }\end{array}$ & $\begin{array}{l}\text { Prospective } \\
\text { clinical trial }\end{array}$ \\
\hline Liem, et al. (2018). ${ }^{17}$ & Netherland & 53 & $70 \pm 12$ & 66 & 74 & $\begin{array}{l}\text { Differentiating benign/ } \\
\text { malignant lesion, grading high/ } \\
\text { low-grade malignant tumor }\end{array}$ & $\begin{array}{l}\text { Prospective } \\
\text { clinical trial }\end{array}$ \\
\hline Liu, et al. (2012). ${ }^{18}$ & USA & 57 & NR & 78 & NR & Grading high/low-grade tumor & $\begin{array}{l}\text { Prospective } \\
\text { clinical trial }\end{array}$ \\
\hline Liu, et al. (2011). ${ }^{19}$ & USA & 29 & $71(28-90)$ & 89 & NR & $\begin{array}{l}\text { Differentiating benign/ } \\
\text { malignant lesion }\end{array}$ & $\begin{array}{l}\text { Prospective } \\
\text { clinical trial }\end{array}$ \\
\hline Lucas, et al. (2019). ${ }^{20}$ & Netherland & 53 & NR & 72 & $N R$ & $\begin{array}{l}\text { Differentiating benign/ } \\
\text { malignant lesion, grading high/ } \\
\text { low-grade malignant tumor }\end{array}$ & $\begin{array}{l}\text { Prospective } \\
\text { clinical trial }\end{array}$ \\
\hline Marien, et al. (2017). ${ }^{21}$ & France & 21 & $68(51-82)$ & 21 & $N R$ & $\begin{array}{l}\text { Differentiating benign/ } \\
\text { malignant lesion, grading high/ } \\
\text { low-grade malignant tumor }\end{array}$ & $\begin{array}{l}\text { Prospective } \\
\text { clinical trial }\end{array}$ \\
\hline Wu, et al. (2019). ${ }^{22}$ & $\begin{array}{l}\text { People's } \\
\text { Republic } \\
\text { of China }\end{array}$ & 21 & $61(32-81)$ & 21 & 81 & $\begin{array}{l}\text { Differentiating benign/ } \\
\text { malignant lesion, grading high/ } \\
\text { low-grade malignant tumor }\end{array}$ & $\begin{array}{l}\text { Prospective } \\
\text { clinical trial }\end{array}$ \\
\hline
\end{tabular}

NR, not reported; Age, presented either in mean \pm SD or mean (range)

Table 3. Systematic review table of CLE's performance on diagnosing bladder cancer

\begin{tabular}{|c|c|c|c|c|c|c|c|c|c|}
\hline \multirow[t]{2}{*}{ Author } & \multirow[t]{2}{*}{ CLE specification } & \multirow[t]{2}{*}{ Pattern } & \multicolumn{2}{|c|}{$\begin{array}{l}\text { Malignancy } \\
\text { differentiating } \\
\text { accuracy }\end{array}$} & \multicolumn{2}{|c|}{$\begin{array}{l}\text { Low-grade tumor } \\
\text { differentiating } \\
\text { accuracy }\end{array}$} & \multicolumn{2}{|c|}{$\begin{array}{l}\text { High-grade tumor } \\
\text { differentiating } \\
\text { accuracy }\end{array}$} & \multirow[t]{2}{*}{ Quality } \\
\hline & & & Sens & Spec & Sens & Spec & Sens & Spec & \\
\hline $\begin{array}{l}\text { Freund, et al. } \\
2019 .{ }^{15}\end{array}$ & $\begin{array}{l}2.7 \mathrm{Fr} \text { probe } \\
\text { UroFlex }\end{array}$ & $\mathrm{pCLE}$ & NR & NR & $76.47 \%+$ & $63.16 \%+$ & $63.16 \%+$ & $76.47 \%+$ & Good \\
\hline $\begin{array}{l}\text { Lee, et al. } \\
2019 .{ }^{16}\end{array}$ & $\begin{array}{l}\text { 2.5-mm probe } \\
\text { GastrFlex }\end{array}$ & $\mathrm{pCLE}$ & $91.67 \%$ & $73.91 \%$ & $66.67 \%+$ & $94.55 \%+$ & $94.55 \%+$ & $66.67 \%+$ & Good \\
\hline $\begin{array}{l}\text { Liem, et al. } \\
\text { (A) 2018. }{ }^{17}\end{array}$ & $\begin{array}{l}\text { 2.6-mm probe } \\
\text { Cystoflex }\end{array}$ & pCLE & $96.15 \%$ & $28.57 \%$ & $76.00 \%$ & $75.61 \%$ & $70.37 \%$ & $69.23 \%$ & Good \\
\hline $\begin{array}{l}\text { Liem, et al. (B) } \\
\text { 2018. }^{17}\end{array}$ & $\begin{array}{l}\text { 2.6-mm probe } \\
\text { Cystoflex }\end{array}$ & $\mathrm{pCLE}+\mathrm{WLC}$ & $92.31 \%$ & $50.00 \%$ & $80.00 \%$ & $78.05 \%$ & $66.67 \%$ & $79.49 \%$ & Good \\
\hline $\begin{array}{l}\text { Liu, et al. (A) } \\
2012 .{ }^{18}\end{array}$ & $\begin{array}{l}\text { 1.4-mm probe } \\
\text { AlveoFlex }\end{array}$ & $\mathrm{pCLE}$ & NR & NR & $58.82 \%$ & $81.97 \%$ & $54.55 \%$ & $82.22 \%$ & Fair \\
\hline $\begin{array}{l}\text { Liu, et al. (B) } \\
2012 .{ }^{18}\end{array}$ & $\begin{array}{l}\text { 1.4-mm probe } \\
\text { AlveoFlex }\end{array}$ & $\mathrm{pCLE}+\mathrm{WLC}$ & NR & NR & $64.71 \%$ & $80.33 \%$ & $66.67 \%$ & $80.00 \%$ & Fair \\
\hline $\begin{array}{l}\text { Liu, et al. } \\
2011 .^{19}\end{array}$ & $\begin{array}{l}\text { 1.4-mm probe } \\
\text { AlveoFlex }\end{array}$ & $\mathrm{pCLE}+\mathrm{WLC}$ & $93.10 \%$ & $96.67 \%$ & NR & NR & NR & NR & Fair \\
\hline $\begin{array}{l}\text { Lucas, et al. } \\
2019 .{ }^{20}\end{array}$ & $\begin{array}{l}\text { 2.6-mm probe } \\
\text { Cystoflex }\end{array}$ & $\mathrm{pCLE}+\mathrm{WLC}$ & $81.58 \%$ & $78.57 \%$ & $79.17 \%+$ & $85.71 \%+$ & $85.71 \% \dagger$ & $79.17 \%+$ & Fair \\
\hline $\begin{array}{l}\text { Marien, et al. } \\
2017 . .^{21}\end{array}$ & $\begin{array}{l}\text { Single-band } 2.5-\mathrm{mm} \\
\text { probe GastroFlex and } \\
\text { dual-band Ultra Mini } \\
\text { O-Probe (prototype) }\end{array}$ & $\mathrm{pCLE}+\mathrm{HAL}$ & $53.33 \%$ & $100.00 \%$ & $71.43 \%$ & $100.00 \%$ & $37.50 \%$ & $100.00 \%$ & Good \\
\hline $\begin{array}{l}\text { Wu, et al. } \\
2019 .^{22}\end{array}$ & $\begin{array}{l}\text { 2.6-mm probe } \\
\text { Cystoflex }\end{array}$ & $\mathrm{pCLE}+\mathrm{WLC}$ & $100.00 \%$ & $50.00 \%$ & $85.71 \%$ & $85.71 \%$ & $80.00 \%$ & $90.91 \%$ & Good \\
\hline
\end{tabular}

NR, not reported; $\dagger$, differentiating low-grade and high-grade neoplasm only; pCLE, probe confocal laser endomicroscopy; WLC, white-light cystoscopy; HAL, Hexylaminolevulinate blue light cystoscopy; FLUO, fluorescein; Sens, sensitivity; Spec, specificity 


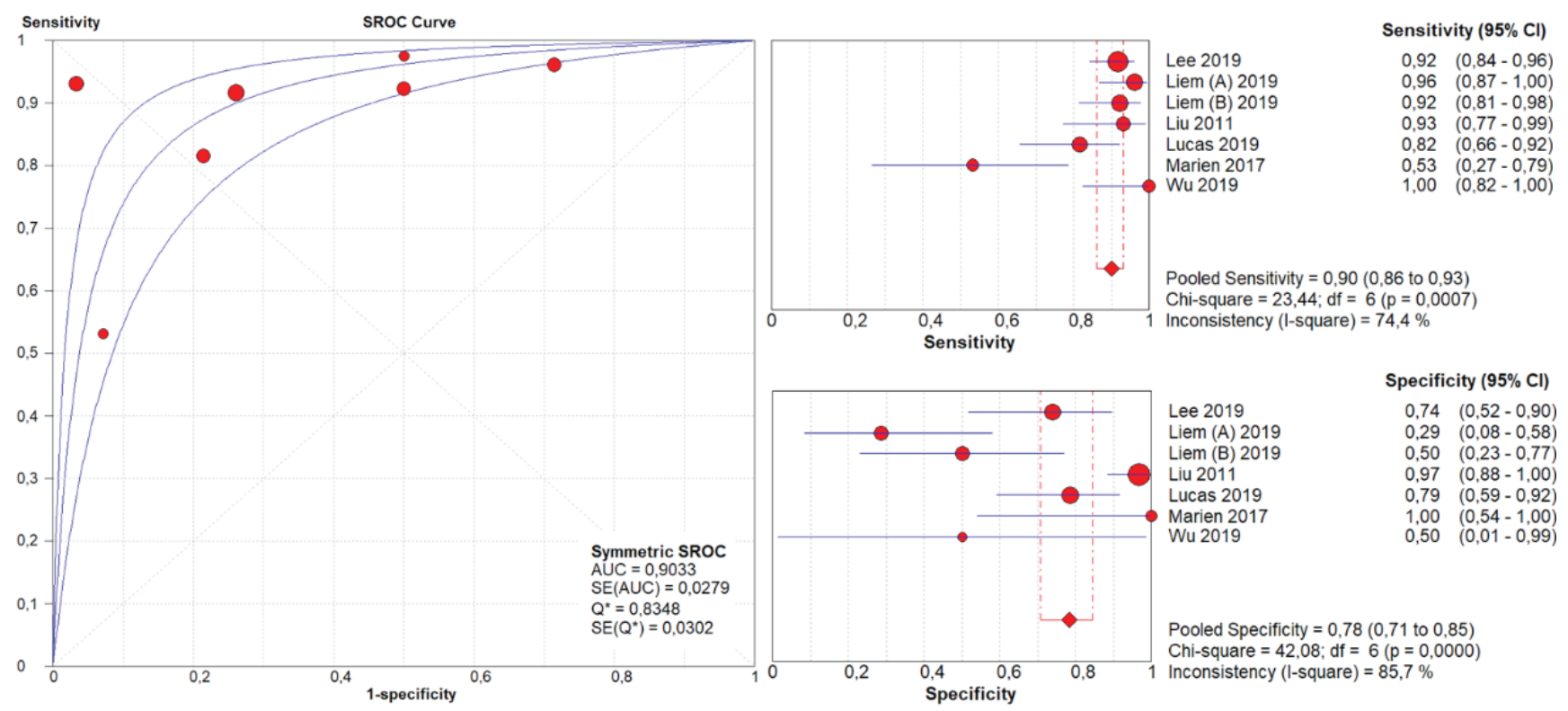

Figure 3. ROC curve and forest plot of malignant lesion differentiating performance

Table 4. Subgroup analysis for several pCLE patterns on diagnosing bladder cancer

\begin{tabular}{lllll}
\hline Pattern & N & Sensitivity & Specificity & AUC \\
\hline$p C L E$ & 2 & $0.932(0.879,0.967)$ & $0.568(0.395,0.729)$ & N/A \\
pCLE + WLC & 4 & $0.906(0.844,0.949)$ & $0.846(0.762,0.909)$ & $0.9483(0.037)$ \\
$p C L E+H A L$ & 1 & $0.533(0.266,0.787)$ & $1.000(0.824,1.000)$ & N/A
\end{tabular}

$\mathrm{N}$, number of experiments; AUC, area under curve; N/A, not available, the number of studies involved is less than three; PCLE, probe confocal laser endomicroscopy; WLC, white-light cystoscopy; HAL, Hexylaminolevulinate blue light cystoscopy

\section{Low-grade differentiating accuracy}
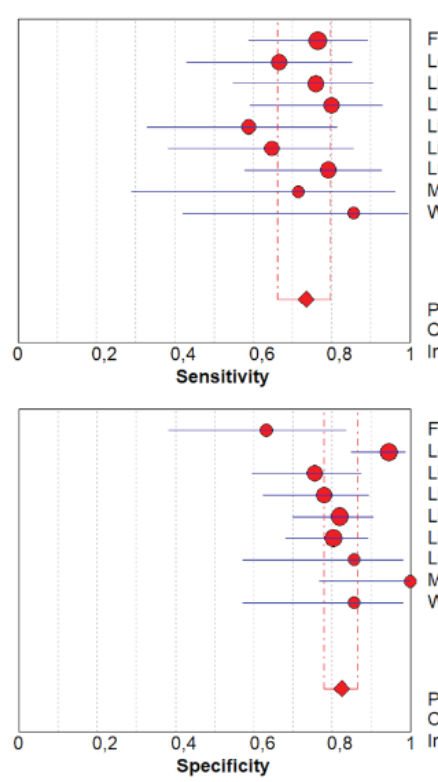

Freund 2019

ee 2019

Liem (A) 2019

iu (B) 2012

Lucas 2019
Marien 2017

Wu 2019

$\begin{array}{lrc}\text { Freund 2019 } & 0,76 & (0,59-0,89 \\ \text { Lee 2019 } & 0,67 & (0,43-0,85 \\ \text { Liem (A) 2019 } & 0,76 & (0,55-0,91 \\ \text { Liem (B) 2019 } & 0,80 & (0,59-0,93 \\ \text { Liu (A) 2012 } & 0,59 & (0,33-0,82 \\ \text { Liu (B) 2012 } & 0,65 & (0,38-0,86 \\ \text { Lucas 2019 } & 0,79 & (0,58-0,93 \\ \text { Marien 2017 } & 0,71 & (0,29-0,96 \\ \text { Wu 2019 } & 0,86 & (0,42-1,00\end{array}$

Pooled Sensitivity $=0,73(0,66$ to 0,80$)$ Chi-square $=4,69 ; \mathrm{df}=8(\mathrm{p}=0,7906)$
Inconsistency $($ (I-square $)=0,0 \%$
Specificity $(95 \% \mathrm{Cl})$
$0,63 \quad(0,38-0,84$
$0,95 \quad(0,85-0,99$
$0,76 \quad(0,60-0,88$
$0,78 \quad(0,62-0,89$
$0,82 \quad(0,70-0,91$
$\begin{array}{ll}0,80 & (0,68-0,89 \\ 0,86 & (0,57-0,98\end{array}$
$\begin{array}{ll}0,86 & (0,57-0,98 \\ 1,00 & (0,77-1,00\end{array}$
$0,86 \quad(0,57-0,98$ Pooled Specificity $=0,83(0,78$ to 0,87$)$
Chi-square $=18,75 ;$ df $=8(p=0,0162)$ nconsistency (l-square) $=57,3 \%$

Figure 4. Forest plot of CLE's neoplasm grading performance

High-grade differentiating accuracy

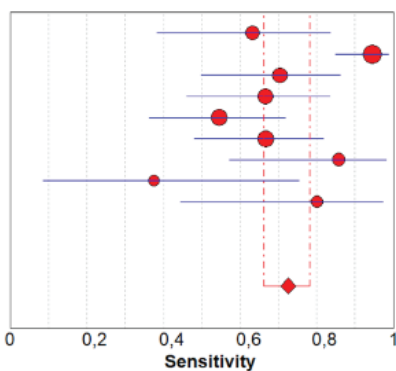

Freund 2019 Lee 2019 Liem (A) 2019
Liem (B) 2019 Liu (A) 2012 Liu (B) 2012 $0,67 \quad(0,48-0,82$

Marien $2017 \quad 0,38 \quad(0,09-0,76$ $0,80 \quad(0,44-0,97$

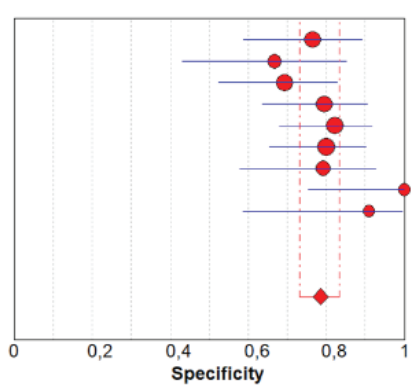
Pooled Sensitivity $=0,73$ ( 0,66 to 0,78$)$ Inconsistency (I-square) $=73,8 \%$

Sensitivity $(95 \% \mathrm{Cl})$

$0,63 \quad(0,38-0,84$

$0,95 \quad(0,85-0,99$

$0,70 \quad(0,50-0,86$

$0,67 \quad(0,46-0,83$

$0,55 \quad(0,36-0,72$

$0,80 \quad(0,44-0,97$

\section{\begin{tabular}{l}
$=0,0002$ \\
\hline
\end{tabular}}

Specificity $(95 \% \mathrm{Cl})$ $0,67 \quad(0,43-0,85$

$0,69 \quad(0,52-0,83$

$0,79 \quad(0,64-0,91$ :

$0,82 \quad(0,68-0,92$ :

$0,80 \quad(0,65-0,90$

$0,79 \quad(0,58-0,93:$ $\begin{array}{ll}1,00 & (0,75-1,00 \\ 0,91 & (0,59-1,00\end{array}$ 
CLE's specificity in determining malignant lesions is not as excellent as its sensitivity. Four out of 7 experiments reported specificity at $>70 \%$. However, the other 3 showed very low results. After we conducted a meta-analysis with the random effect model, we found a pooled specificity of $78.1 \%(0.71,0.85)$. The area under the Curve was recorded at 0.9033 (0.0279), which indicates that CLE has high sensitivity and a low falsepositive rate. The results of the pooling effect estimate are in Figure 3.

Subgroup analyzes were performed to assess the performance of each pCLE technique pattern. pCLE alone has high sensitivity and low specificity. Combining pCLE with WLC increased PCLE specificity while maintaining pCLE sensitivity above $90 \%$. When pCLE was combined with Hexylaminolevulinate blue light cystoscopy (HAL), the specificity was perfect, but the sensitivity decreased dramatically to $53 \%$ (Table 4).

\section{CLE accuracy in grading tumor}

The CLE technique was designed not only to determine malignant or benign lesions but also to help diagnose the neoplasm degree. Our meta-analysis found that CLE performance determined the neoplasm degree not as good as CLE performance in determining benign or malignant lesions. We also found CLE's sensitivity and specificity in determining low-grade tumors of $73 \%$ $(0.66,0.80)$ and $83 \%(0.78,0.87)$, respectively. The Area Under Curve (AUC) was recorded at 0.8377 .

We also obtained the same thing in CLE performance in determining high-grade tumors. The sensitivity of CLE to determine high-grade tumors was only $73 \%$ (0.66, $0.78)$, while the specificity was $79 \%(0.73,0.83)$. AUC was recorded at 0.8110 . In addition, all results were heterogeneous, except for the sensitivity of CLE in diagnosing benign tumors (Figure 4).

\section{DISCUSSION}

Bladder cancer is one of the most malignant cancers globally, placed as the sixth most common malignancy [1]. Multiple advancements in endoscopic technology have been designed to enhance the sensitivity and specificity of the diagnostic tools. Confocal laser endomicroscopy (CLE) and optical coherence tomography (OCT) are used as microscopic imaging and are useful for tumor staging and grading [12]. CLE is an optical biopsy equipped with a high microscopic resolution with images comparable with a traditional histopathology biopsy sample. CLE is by far one of the optical biopsy technologies that can differentiate between the low and high grades of bladder cancer [10].

A systematic review was conducted by Brunckhorst et al. [23]. However, the systematic review was superficial in reviewing CLE's performance in diagnosing bladder cancer, as only one study was included, which reported a proper effect estimate of diagnostic study in the form of sensitivity and specificity [23]. On this basis, the current study attempts to re-explore the performance of CLE in diagnosing bladder cancer, which has never been comprehensively reported before. Our meta-analysis found that CLE had an excellent overall performance in diagnosing bladder cancer, with sensitivity and specificity of $90.2 \%(0.86,0.93)$ and $78.1 \%$ (0.71, 0.85). Compared to WLC, CLE has a better sensitivity performance in diagnosing bladder cancer, while the specificity is not much different. Subgroup analysis also uncovered that combining the pCLE technique with WLC would increase CLE's specificity (56.8\% versus $84.6 \%$ ) and maintaining its sensitivity above $90 \%$ (93.2\% versus $90.6 \%$ ).

Moreover, CLE is a sophisticated high-resolution imaging modality that makes it possible to carry out probe-based optical in vivo tissue examinations during endoscopy. Initially, this method was used to improve the accuracy of the WLC examination through improved visualization of flat lesions, differentiation of benign and malignant tumors, and determination of tumor boundaries [24]. WLC is a standard imaging modality for bladder cancer; however, this technique has a false negative rate that is high enough so that sensitivity is relatively low. In clinical settings, WLC is involved as an initial survey and is used to guide CLE to the intended area; thus, the use of CLE and WLC is highly recommended and has essential clinical relevance [13].

It is in line with what we encountered in this metaanalysis in subgroup analysis. The use of pCLE alone had a pooled sensitivity of $93.2 \%(0.879,0.967)$. The merging of pCLE with WLC reduced its sensitivity but remained above $90 \%[90.6 \%(0.844,0.949)]$. On the other hand, the specificity of pCLE alone was $56.8 \%(0.395$, 0.729). The pooled specificity of experiments using pCLE with WLC was recorded at $84.6 \%(0.395,0.729)$.

CLE is also designed to grade neoplasms, as CLE can visualize the tissue microarchitecture. Our meta-analysis found that the accuracy of CLE in grading neoplastic tissue was not as excellent as its accuracy in excluding benign lesions. CLE's sensitivity in distinguishing lowgrade tumors from high-grade or non-neoplastic tissue was only $73 \%(0.66,0.80)$. Conversely, the sensitivity of CLE in distinguishing high-grade tumors from lowgrade or non-neoplastic tissue was $73 \%(0.66,0.78)$. Specificity for each of these abilities was only $83 \%(0.78$, $0.87)$ and $79 \%(0.73,0.83)$, respectively. However, the determination of the lesion grade was done through an interobserver agreement, so the low sensitivity and specificity could occur due to an imperfect agreement in determining the lesion degree.

By far, so many imaging modalities have been developed to assist urologists in determining the malignancy of bladder lesions. However, no clinical studies compared the accuracy of each modality comprehensively 
and reliably. In vivo studies in animals have been reported by Ren et al. [25], who used transgenic mice with bladder carcinoma in situ. The sensitivity and specificity of WLC, OCT, NBI, and fluorescence cystoscopy (PDD) were $3 \%$ and $78 \%, 93 \%$ and $94 \%, 90 \%$ and $28 \%$, $45 \%$ and $100 \%$, respectively. However, the experiment's results on animals might be different in humans. Therefore, with considerable ethical challenges, further investigation is needed to be carried out on humans.

Although this meta-analysis could explain CLE's performance in the diagnosis of bladder cancer, several important points are needed to be reviewed further. First, not all studies carried out CLE according to general clinical settings, which are real-time and in vivo. Second, no studies reported the applicability of this modality in terms of costs and benefits. Third, the ultimate criteria for CLE diagnosis and lesion/tumor grading should have been established and tested for validity and reliability.

However, several factors might confound the interpretation of this review. First, we compiled all studies with CLE diagnostic accuracy outcomes without regard to diagnostic patterns/techniques due to limited studies. Heterogeneity of inter-study techniques was thought to confound the interpretation of the meta-analysis results. Second, we found reasonably high heterogeneity in each analysis. After we conducted the subgroup analysis, we have not been able to address the high heterogeneity problem. Third, we included studies with various CLE specifications. Even though it is unlikely, we thought this would confound the reports of each study.

\section{CONCLUSIONS}

CLE has good accuracy in distinguishing malignant and benign tumors. Grading tumors with this modality is also accurate. The use of pCLE coupled with WLC will also increase its specificity.

\section{DECLARATIONS}

\section{Competing of Interest}

The authors declare no competing interest in this study.

\section{Acknowledgment}

The authors wish to thank the Department of Urology Cipto Mangunkusumo Hospital Jakarta.

\section{REFERENCES}

1. National Cancer Institute. Cancer stat facts: bladder cancer [Internet]. National Cancer Institute. 2020 [cited 2020 May 22]. Available from: https://seer. cancer.gov/statfacts/html/urinb.html

2. Cancer facts \& figures 2019 [Internet]. 2019 [cited 2020 May 22]. Available from: https://www.cancer. org/content/dam/cancer-org/research/cancer-facts- and-statistics/annual-cancer-facts-and-figures/2019/ cancer-facts-and-figures-2019.pdf

3. Wong MCS, Fung FDH, Leung $C$, et al. The global epidemiology of bladder cancer: a joinpoint regression analysis of its incidence and mortality trends and projection OPEN. Sci Rep. 2018;8:1129.

4. Miyazaki J, Nishiyama H. Epidemiology of urothelial carcinoma. Int J Urol. 2017;24(10):730-734.

5. Rezaianzadeh A, Mohammadbeigi A, Mobaleghi J, Mohammadsalehi N. Survival analysis of patients with bladder cancer, life table approach. J -Life Health. 2012;3(2):88-92.

6. Andreassen BK, Aagnes B, Gislefoss R, et al. Incidence and Survival of urothelial carcinoma of the urinary bladder in Norway 1981-2014. BMC Cancer. 2016;16(1):799.

7. Zhu C-Z, Ting $\mathrm{H}-\mathrm{N}, \mathrm{Ng} \mathrm{K}-\mathrm{H}$, Ong T-A. A review on the accuracy of bladder cancer detection methods. J Cancer. 2019;10(17):4038-44.

8. Oude Elferink P, Witjes JA. Blue-light cystoscopy in the evaluation of non-muscle-invasive bladder cancer. Ther Adv Urol. 2014;6(1):25-33.

9. Shen Y-J, Zhu Y-P, Ye D-W, et al. Narrow-band imaging flexible cystoscopy in the detection of primary non-muscle invasive bladder cancer: a "second look" matters? Int Urol Nephrol. 2012;44(2):451-7.

10. Zlatev DV, Altobelli E, Liao JC. Advances in imaging technologies in the evaluation of high-grade bladder cancer. Urol Clin North Am. 2015;42(2):147-57.

11. Chen SP, Liao JC. Confocal laser endomicroscopy of bladder and upper tract urothelial carcinoma: a new era of optical diagnosis? Curr Urol Rep. 2014;15(9):437.

12. Knoedler JJ, Raman JD. Advances in the management of upper tract urothelial carcinoma: improved endoscopic management through better diagnostics. Ther Adv Urol. 2018;10(12):421-9.

13. Chang TC, Liu J-J, Hsiao ST, et al. Interobserver agreement of confocal laser endomicroscopy for bladder cancer. J Endourol. 2013;27(5):598-603.

14. Whiting PF, Rutjes AWS, Westwood ME, Mallett $S$, Deeks JJ, Reitsma JB, et al. QUADAS-2: a revised tool for the quality assessment of diagnostic accuracy studies. Ann Intern Med. 2011;18;155(8):529-36.

15. Freund JE, Liem EIML, Savci-Heijink CD, Baard J, Kamphuis GM, de la Rosette JJMCH, et al. Confocal laser endomicroscopy for upper tract urothelial carcinoma: validation of the proposed criteria and proposal of a scoring system for real-time tumor grading. World J Urol. 2019;37(10):2155-64.

16. Lee J, Jeh SU, Koh DH, Chung DY, Kim MS, Goh HJ, et al. Probe-Based Confocal Laser Endomicroscopy During Transurethral Resection of Bladder Tumors Improves the Diagnostic Accuracy and Therapeutic Efficacy. Ann Surg Oncol. 2019;26(4):1158-65. 
17. Liem EIML, Freund JE, Savci-Heijink CD, de la Rosette JJMCH, Kamphuis GM, Baard J, et al. Validation of confocal laser endomicroscopy features of bladder cancer: The next step towards real-time histologic grading. Eur Urol Focus. 2020;6(1):81-7.

18. Liu J-J, Chang TC, Pan Y, et al. Next generation of optical diagnostics for bladder cancer using probebased confocal laser endomicroscopy. In: Photonic Therapeutics and Diagnostics VIII [Internet]. International Society for Optics and Photonics; 2012 [cited 2020 Jun 10]. p. 820716. Available from: https://www.spiedigitallibrary.org/conferenceproceedings-of-spie/8207/820716/Next-generationof-optical-diagnostics-for-bladder-cancer-usingprobe/10.1117/12.907623.short

19. Liu J-J, Wu K, Adams W, et al. Real time diagnosis of bladder cancer with probe-based confocal laser endomicroscopy. In: Imaging, Manipulation, and Analysis of Biomolecules, Cells, and Tissues IX [Internet]. International Society for Optics and Photonics; 2011 [cited 2020 Jun 10]. p. 79021V. Available from: https://www.spiedigitallibrary.org/ conference-proceedings-of-spie/7902/79021V/Realtime-diagnosis-of-bladder-cancer-with-probe-basedconfocal/10.1117/12.874243.short
20. Lucas M, Liem EIML, Savci-Heijink CD, et al. Toward automated in vivo bladder tumor stratification using confocal laser endomicroscopy. J Endourol. 2019;33(11):930-7.

21. Marien A, Rock A, Maadarani KE, et al. Urothelial tumors and dual-band imaging: A new concept in confocal laser endomicroscopy. J Endourol. 2017;31(5):538-44.

22. Wu J, Wang Y-C, Dai B, et al. Optical biopsy of bladder cancer using confocal laser endomicroscopy. Int Urol Nephrol. 2019;51(9):1473-9.

23. Brunckhorst O, Ong QJ, Elson D, Mayer E. Novel real-time optical imaging modalities for the detection of neoplastic lesions in urology: a systematic review. Surg Endosc. 2019;33(5):1349-67.

24. Chen SP, Liao JC. Confocal laser endomicroscopy of bladder and upper tract urothelial carcinoma: A new era of optical diagnosis? Curr Urol Rep. 2014;15(9):437.

25. Ren H, Park KC, Pan R, et al. Early detection of carcinoma in situ of the bladder: a comparative study of white light cystoscopy, narrow band imaging, 5-ALA fluorescence cystoscopy and 3-dimensional optical coherence tomography. J Urol. 2012;187(3):1063-70. 